СЕЛЕЦЬКИЙ В.С., к.т.н., провідний інженер ВП «Львівське відділення» філії «ГІОЦ» АТ «Укрзалізниця»

\title{
Мережі Петрі і комплексні числа
}

У статті проведено розширення можливостей комплексної позиції виду $n$-iт (вихідна предикатна позиція), розроблено комплексну позицію виду $n+i m$ (вхідна предикатна позиція) $i$ реалізовано механізм роботи комплексних позицій видів $n-i m$ i $n+i m$.

Проведені розширення мереж Петрі на підставі побудованих підмереж з передумовною комплексною позицією виду $n$-im $i$ післяумовною комплексною позицією виду $n+i m$ описано математичною термінологією, відображено за допомогою графічних інтерпретачій $i$ проілюстровано їх застосування на прикладах.

Ключові слова: модель, розиирена мережа Петрі, вихідна предикатна позиція, вхідна предикатна позиція, комплексна позиція виду $n-i m$, комплексна позиція виду $n+i m$.

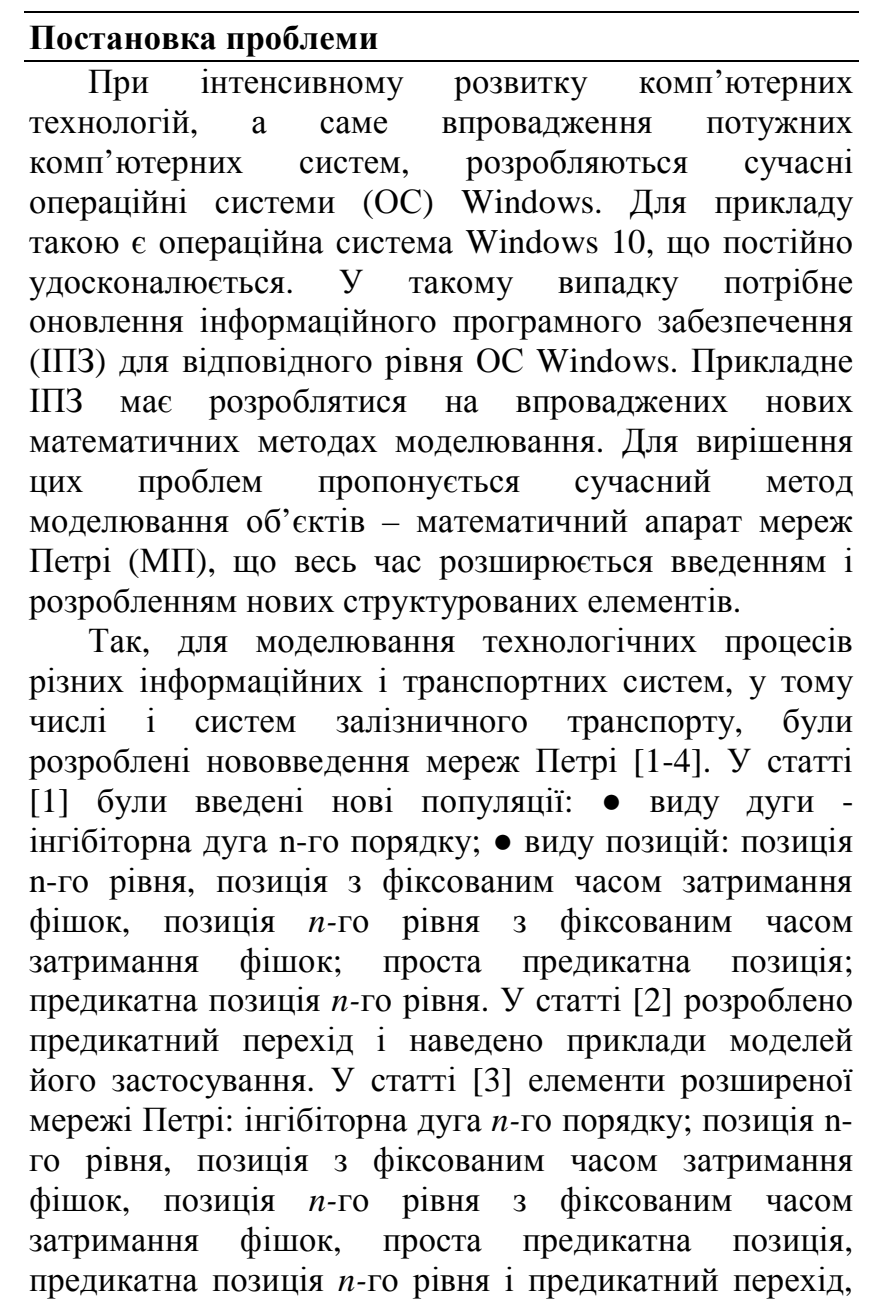

() В. С. Селецький, 2020 описані математичною мовою i відображені за допомогою графічних інтерпретацій, і на наведених прикладах обгрунтовано цінність використання елементів розширеної мережі Петрі для побудови моделей, що описують складні технологічні процеси різних інформаційних і транспортних систем, а в статті [5] введено предикатну узагальнену позицію i предикатну узагальнену позицію $n$-го рівня та на конкретному прикладі відображено залежність компонентів функції маркування для розширеної підмережі 3 вихідною предикатною узагальненою позицію $k$-го рівня i вхідними елементарними позиціями.

За визначенням [1, 2, 3, 5], предикатна позиція (предикатна позиція $n$-го рівня) є завжди вихідною, i для неї позиціями можуть бути тільки проста позиція, позиція з фіксованим часом затримання фішок, позиція $n$-го рівня і позиція $n$-го рівня 3 фіксованим часом затримання фішок.

У статті [6] описано математичною мовою мереж Петрі передумовний і післяумовий оператори циклу. На підставі наведених обгрунтувань виникла потреба в розробленні нової популяції виду позиції - вхідної предикатної позиції.

\section{Постановка задачі}

У статті поставлено мету удосконалити вихідну предикатну позицію (комплексна позиція виду $n-i m)$ і розробити вхідну предикатну позицію (комплексна позиція виду $n+i m$ ), реалізувати механізм роботи комплексних позицій видів $n-i m$ i $n+i m$, а також описати динаміку функціонування комплексних позицій $n-i m$ і $n+i m$; на прикладах обгрунтовати мету застосування введених комплексних позицій видів $n-i m$ і $n+i m$. 


\section{Вирішення проблеми}

Множина невід'ємних цілих чисел $Z^{\geq}$це об'єднання множини натуральних чисел $N=\{1,2,3, \ldots\}$ i числа 0, іншими словами $Z^{\geq}=N \cup 0=\{0,1,2,3, \ldots\}$.

Визначення 1. Цілочисельне комплексне число - це комплексне число $z=n+i m$, де $n \in Z^{\geq}$і $m \in Z^{\geq}$.

\section{Передумова}

Визначення 2. Передумовна комплексна позиція це позиція, що задається комплексним цілочисельним числом $n-i m$, де перше число $n \in Z^{\geq}$вказує на номер спрацювання переходу, а друге число $m \in Z^{\geq}$ вказує на кількість фішок, яка вилучається після спрацювання вказаного переходу.

Нехай у підмережі $S_{\mathrm{Pr}}^{\prime}$ (рис. 1) передумовна комплексна позиція $P_{0}$ має початкове марковання $m\left(P_{0}\right)=n-i m$, а позиції $P_{i}^{\prime}$ для $1 \leq i \leq k$ мають початкове марковання $m\left(P_{i}^{\prime}\right)$ для $1 \leq i \leq k$. Якщо існує такий перехід $t_{i}^{\prime} \in T$, де $1 \leq i \leq k$ для якого виконуються умови $i=n$ і $m \geq 1$, то перехід $t_{i}^{\prime}$ має запуститися. $\mathrm{y}$ результаті запуску переходу $t_{i}^{\prime}$ марковання підмережі змінюється на нове марковання $M^{\prime}$. Тоді нове марковання позиції $P_{0}$ буде визначатися формулою $m^{\prime}\left(P_{0}\right)=m\left(P_{0}\right)-m$, нові марковання позицій $P_{k 1}^{\prime}$ для $1 \leq k 1 \leq n-1$ будуть визначатися формулами $m^{\prime}\left(P_{k 1}^{\prime}\right)=m\left(P_{k 1}^{\prime}\right)$, $1 \leq k 1 \leq n-1$, нове марковання позиції $P_{i=n}$ буде визначатися формулою $m^{\prime}\left(P_{i=n}^{\prime}\right)=m\left(P_{i=n}^{\prime}\right)+m$ i нові марковання позицій $P_{k 2}$ для $n+1 \leq k 2 \leq k$ будуть визначатися формулами $m^{\prime}\left(P_{k 2}^{\prime}\right)=m\left(P_{k 2}^{\prime}\right) \quad$ для $n+1 \leq k 2 \leq k$.

Іншими словами, перехід $t_{i}$ запуститься, якщо:

$$
\begin{aligned}
& \left(\exists t_{i}^{\prime} \in T, 1 \leq i \leq k\right) \wedge(i=n) \wedge(m \geq 1) \wedge(\mathrm{Pr}=1) \\
& \Rightarrow\left(m^{\prime}\left(P_{0}\right)=m\left(P_{0}\right)-m\right) \wedge\left(m^{\prime}\left(P_{k 1}^{\prime}\right)=\right. \\
& \left.m\left(P_{k 1}^{\prime}\right), 1 \leq k 1 \leq n-1\right) \wedge\left(m^{\prime}\left(P_{i=n}^{\prime}\right)=m\left(P_{i=n}^{\prime}\right)+m\right) \\
& \wedge\left(m^{\prime}\left(P_{k 2}^{\prime}\right)=m\left(P_{k 2}^{\prime}\right), n+1 \leq k 2 \leq k\right)
\end{aligned}
$$

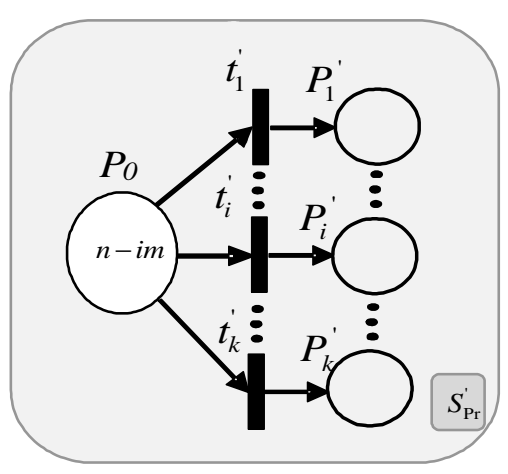

Рис. 1. Підмережа $S_{\mathrm{Pr}}^{\prime}$

з передумовною комплексною позицією

У моделі $S^{\prime} \quad[1,4,7,8,9]$, розробленій на базі підмережі $S_{\operatorname{Pr}}^{\prime} \quad$ (рис. 2) позиція $P_{01}$ моделює продукцію виду $v_{1}$, яку випускає виробник 1 , позиція $P_{02}$ моделює продукиію виду $v_{2}$, яку випускає виробник $2, \ldots$, позиція $P_{0 l}$ моделює продукцію виду $v_{l}$, яку випускає виробник $l$.

Вихідна передумовна комплексна позиція ' $P_{1}$ задається комплексним цілочисельним числом $n_{1}-i m_{1}$, де $n_{1}$ вказує на номер спрацювання переходу $t_{\mathrm{i}}=t_{n_{1}}$, де $1 \leq i \leq k$ i $1 \leq n_{1} \leq k \quad$ (замовник $i\left(i=n_{1}\right)$ повинен отримати продукцію виду $\left.\nu_{\mathrm{i}}\right)$, вхідна передумовна комплексна позиція $P_{2}$ задається комплексним цілочисельним числом $n_{2}-i m_{2}$, де $n_{2}$ вказує на номер спрацювання переходу $t_{\mathrm{i}}=t_{n_{2}}$, де $1 \leq i \leq k \quad$ i $1 \leq n_{2} \leq k \quad$ (замовник $i \quad\left(i=n_{2}\right)$ повинен отримати продукцію виду $\left.v_{\mathrm{i}}\right), \ldots$, вихідна передумовна комплексна позиція ' $P_{l}$ задається комплексним цілочисельним числом $n_{l}-i m_{l}$, де $n_{l}$ вказує на номер спрацювання переходу $t_{\mathrm{i}}=t_{n_{l}}$, де $1 \leq i \leq k \quad$ i $1 \leq n_{l} \leq k \quad$ (замовник $i \quad\left(i=n_{l}\right)$ повинен отримати продукиію виду $\left.v_{\mathrm{i}}\right)$.

Позиція $P_{11}^{\prime}$ моделює замовника 1 , якому потрібна продукиія виду $v_{\mathrm{n}_{1}}$, позиція $P_{12}^{\prime}-$ замовника 2 , якому потрібна продукція виду $v_{\mathrm{n}_{2}}, \ldots$, позиція $P_{1 k}^{\prime}$ - замовника $k$, якому потрібна продукція виду $v_{\mathrm{n}_{\mathrm{k}}}$. 
Переходи $t_{0 i}^{\prime} \in T, \quad$ де $\quad 1 \leq i \leq l \quad$ імітують надходження продукиії виду $v_{\mathrm{i}}$, де $1 \leq i \leq l$, у позиції ' $P_{i}$, де $1 \leq i \leq l$ для задавання числа $n_{i}$, де $1 \leq i \leq l$, яке вказує на замовника $j$, де $1 \leq j \leq k$ продукиії виду $v_{\mathrm{i}}$, де $1 \leq i \leq l$, і числа $m_{i}$, де $1 \leq i \leq l$, яке вказує на кількість умовних одиниць замовленої продукції.

Переходи $t_{i}^{\prime} \in T, \quad$ де $1 \leq i \leq k, \quad$ імітують надходження продукиії виду $l_{\mathrm{i}}$, де $1 \leq i \leq l$, у позиції $P_{1 j}^{\prime}$, де $1 \leq j \leq k$ (замовникам $j$, де $\left.1 \leq j \leq k\right)$.

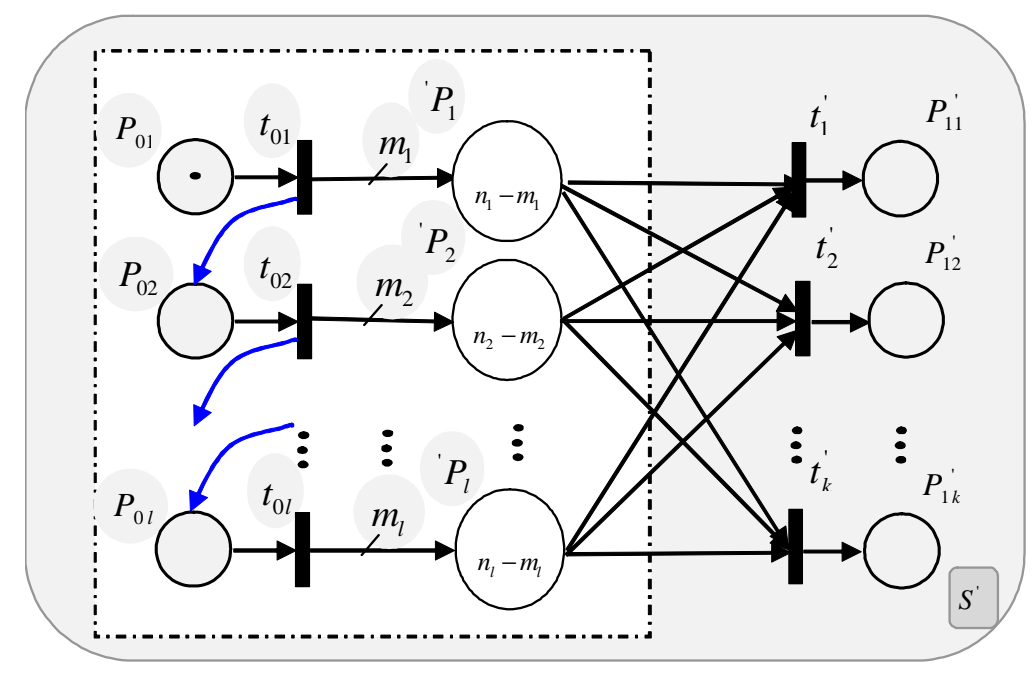

Рис. 2. Модель на базі підмережі $S_{\mathrm{Pr}}^{\prime}$

Модель $S^{\prime}$, описана за допомогою розширеної мережі Петрі, задається матрицями

$$
\begin{aligned}
P^{T} & =\left|\begin{array}{ccccccccccccccccccccccc}
01 & 1 & 1 & . & . & . & 1 & 02 & 2 & 2 & . & . & . & 2 & . & . & . & l & l & . & . & . & l \\
01 & 1 & 2 & . & . & . & k & 02 & 1 & 2 & . & . & . & k & . & . & . & 1 & 2 & . & . & . & k \\
1 & 1 & 1 & . & . & . & 1 & 1 & 1 & 1 & . & . & . & 1 & . & . & . & 1 & 1 & . & . & . & 1
\end{array}\right|, \\
T^{T} & =\left|\begin{array}{ccccccccc}
01 & 1 & 02 & .2 & . & . & . & 0 l & k \\
1 & 11 & 2 & 12 & . & . & . & l & 1 k \\
m_{1} & 1 & m_{2} & 1 & . & . & . & m_{l} & 1
\end{array}\right|
\end{aligned}
$$

і початковими маркуваннями: $m\left(P_{01}\right)=1, m\left(P_{02}\right)=0, \ldots, m\left(P_{0 l}\right)=0, \quad m\left(P_{i}\right)=n_{i}-i m_{i}, \quad$ де $1 \leq i \leq l, m\left(P_{1 j}^{\prime}\right)=0$, де $1 \leq j \leq k$.

Застосування розробленої моделі $S^{\prime}$ розглянемо на прикладі 1 для конкретних даних.

Приклад 1. Склад поїзда на сортувальній гірці поступає в розформування. Поїзд містить три відчепи. Іншими словами, $m\left(P_{01}\right)=1, \quad m\left(P_{02}\right)=0$, $m\left(P_{03}\right)=0, \quad m\left(P_{1}\right)=2-i 32, \quad m\left(P_{2}\right)=1-i 5$, $m\left(P_{3}\right)=3-i 18, \quad m\left(P_{1 j}^{\prime}\right)=0, \quad$ де $\quad 1 \leq j \leq 3 . \quad t_{0 i}$ i $t_{i}^{\prime}$, де $1 \leq i \leq 3$.
Тривалість відчеплень груп вагонів на гірці відповідно задаються часом $f\left(P_{01}\right)=0, f\left(P_{02}\right)=1$, $f\left(P_{03}\right)=1 \quad$ i $\quad f\left(P_{04}\right)=1 . \quad$ Динаміка технологічних процесів роботи моделі $S^{\prime}$ відображена в табл. 1. Загалом переходи $T_{i} \in T$ імітують переходи 
Динамічна таблиця технологічних процесів роботи моделі $S$

\begin{tabular}{|c|c|c|c|c|c|c|c|c|c|c|c|l|}
\hline $\begin{array}{c}\text { Номер } \\
\text { такту }\end{array}$ & $\begin{array}{c}\text { У.о. } \\
\text { ч. }\end{array}$ & $T_{i}$ & $P_{01}$ & $P_{02}$ & $P_{03}$ & $P_{1}$ & ${ }^{\prime} P_{2}$ & $P_{3}$ & $P_{21}^{\prime}$ & $P_{22}^{\prime}$ & $P_{23}^{\prime}$ & \multicolumn{1}{|c|}{ Зауваження } \\
\hline 1 & 0 & $t_{01}$ & 0 & 1 & 0 & $2 / 32$ & $1 / 5$ & $3 / 18$ & 0 & 0 & 0 & Дозвіл на 1-ше відчеплення \\
\hline 2 & 0 & $t_{1}^{\prime}$ & 0 & 1 & 0 & 0 & $1 / 5$ & $3 / 18$ & 32 & 0 & 0 & Виконано 1-ше відчеплення \\
\hline 3 & 1 & $t_{02}$ & 0 & 0 & 1 & 0 & $1 / 5$ & $3 / 18$ & 32 & 0 & 0 & Дозвіл на 2-ге відчеплення \\
\hline 4 & 1 & $t_{2}^{\prime}$ & 0 & 0 & 1 & 0 & 0 & $3 / 18$ & 32 & 5 & 0 & Виконано 2-ге відчеплення \\
\hline 5 & 2 & $t_{03}$ & 0 & 0 & 0 & 0 & 0 & $3 / 18$ & 32 & 5 & 0 & Дозвіл на 3-тє відчеплення \\
\hline 6 & 2 & $t_{3}^{\prime}$ & 0 & 0 & 0 & 0 & 0 & 0 & 32 & 5 & 18 & Виконано 3-тє відчеплення \\
\hline
\end{tabular}

\section{Післяумова}

Визначення 3. Післяумовна комплексна позиція це позиція, що задається комплексним цілочисельним числом $n+i m$, де перше число $n \in Z^{\geq}$вказує на номер спрацювання переходу, а друге число $m \in Z^{\geq}$ вказує на кількість фішок, яка додається після спрацювання вказаного переходу.

Нехай у підмережі $S_{\operatorname{Pr}}$ (рис. 3) позиції ' $P_{i}$ для $1 \leq i \leq k$ мають початкове марковання $m\left(P_{i}\right)$ для $1 \leq i \leq k$, а позиція $P_{0}$ має початкове марковання $m\left(P_{0}\right)$. Якщо існує такий перехід ' $t_{i} \in T$, де $1 \leq i \leq k$, для якого виконуються умови $i=n$ i $m\left(P_{n}\right) \geq m$, то перехід ' $t_{i}$ має запуститися. У результаті запуску переходу ' $t_{i}$ в підмережі $S_{\operatorname{Pr}}$ марковання $M$ змінюється на нове марковання $M^{\prime}$. Тоді нові марковання позицій ' $P_{k 1}$ для $1 \leq k 1 \leq n-1$ будуть визначатися формулами $m^{\prime}\left(P_{k 1}\right)=m\left(P_{k 1}\right)$, $1 \leq k 1 \leq n-1$, нове марковання позиції ' $P_{i=n}$ буде визначатися формулою $m$ ' $\left(P_{i=n}\right)=m\left(P_{i=n}\right)-m$, нові марковання позицій ' $P_{k 2}$ для $n+1 \leq k 2 \leq k$ будуть визначатися формулами $m^{\prime}\left(P_{k 2}\right)=m\left(P_{k 2}\right)$ для $n+1 \leq k 2 \leq k$, нове марковання позиції $P_{0}$ буде визначатися формулою $m^{\prime}\left(P_{0}\right)=m\left(P_{0}\right)+m$.

Іншими словами, перехід ' $t_{i}$ запуститься, якщо $\left(\exists^{\prime} t_{i} \in T, 1 \leq i \leq k\right) \wedge(i=n) \wedge\left(m\left(P_{n}\right) \geq m\right) \Rightarrow$ $\left(m^{\prime}\left(P_{k 1}\right)=m\left(P_{k 1}\right), 1 \leq k 1 \leq n-1\right) \wedge\left(m^{\prime}\left(P_{i=n}\right)=\right.$ $\left.\left.m\left(P_{i=n}\right)-m\right) \wedge\left(m^{\prime}\left(P_{k 2}\right)=m\left(P_{k 2}\right)\right), n+1 \leq k 2 \leq k\right)$ $\wedge\left(m^{\prime}\left(P_{0}\right)=m\left(P_{0}\right)+m\right)$.

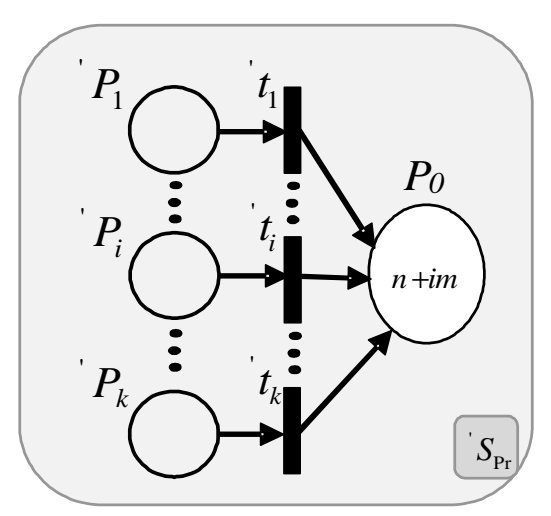

Рис. 3. Підмережа 'S $S_{\mathrm{Pr}}$ з післяумовною комплексною позицією

На рис. 4 наведена модель 'S [1,4,8,9,10,11,12], розроблена на базі підмережі ' $S_{\mathrm{Pr}}$. Позиція ' $P_{11}$ моделює виробника 1, який випускає продукцію виду $v_{\mathrm{n}_{1}}$, позиція ' $P_{12}$ моделює виробника 2 , який випускає продукцію виду $v_{\mathrm{n}_{2}}, \ldots$, позиція ' $P_{1 k}$ моделює виробника $k$, який випускає продукцію виду $v_{\mathrm{n}_{\mathrm{k}}}$, післяумовні комплексні позиції $P_{i}^{\prime}$, де $1 \leq i \leq l$, задаються комплексними цілочисельними числами $n_{i}+i m_{i}$, де $1 \leq i \leq l$. Числа $n_{i}$, де $1 \leq i \leq l$, вказують на замовника продукиї виду $v_{\mathrm{n}_{\mathrm{i}}}$, де $1 \leq i \leq l$, числа $m_{i}$, де $1 \leq i \leq l$, вказують на кількість необхідних умовних одиниць продукції. Позиції $P_{2 i}$, де $1 \leq i \leq l$ моделюють замовників продукиії виду $v_{\mathrm{n}_{\mathrm{i}}}$, де $1 \leq i \leq l$. Позиції $P_{0 i}$, де $1 \leq i \leq l$ відображують ознаки розподілу продукиії замовниками 
(якщо $m\left(P_{0 i}\right)=1$, де $1 \leq i \leq l$, то відбувається розподіл продукції за допомогою післяумовних комплексних позицій $P_{i}$, де $\left.1 \leq i \leq l\right)$. Розподіл продукиіі замовниками відповідно визначається тривалостями часу $f\left(P_{01}\right)=0, f\left(P_{0 i}\right)=1$, де $2 \leq i \leq l$. Переходи ' $t_{1 i} \in T$, де $1 \leq i \leq k$, імітують поставку продукиї виду $v_{\mathrm{n}_{\mathrm{i}}}$, де $1 \leq i \leq k$, переходи $t_{2 j}$ імітують доставку продукції виду $v_{\mathrm{n}_{\mathrm{j}}}$, де $1 \leq j \leq l$, і переходи $t_{j}$ імітують розподіл продукції виду $\quad v_{\mathrm{n}_{\mathrm{j}}}$, де $1 \leq j \leq l$.

Модель 'S, описана за допомогою розширеної мережі Петрі, задається матрицями

$$
\begin{aligned}
& P^{T}=\left|\begin{array}{cccccccccccc}
01 & 11 & 1 & 02 & 12 & 2 & . & . & . & 0 l & 1 k & 2 l \\
1 & 11 & 21 & 2 & 12 & 22 & . & . & . & l & 1 k & 2 l \\
1 & 1 & 1 & 1 & 1 & 1 & . & . & . & 1 & 1 & 1
\end{array}\right| \\
& T^{T}=\left|\begin{array}{ccccccccccccccccccccccccccccc}
1 & 1 & 11 & 11 & . & . & . & 11 & 21 & 2 & 2 & 12 & 12 & . & . & . & 12 & 22 & . & . & . & l & 1 k & 1 k & . & . & . & 1 k & 2 l \\
1 & 02 & 1 & 2 & . & . & . & l & 21 & 2 & 03 & 1 & 2 & . & . & . & l & 22 & . & . & . & l & 1 & 2 & . & . & . & l & 2 l . \\
1 & 1 & 1 & 1 & . & . & . & 1 & 1 & 1 & 1 & 1 & 1 & . & . & . & 1 & 1 & . & . & . & 1 & 1 & 1 & . & . & . & 1 & 1
\end{array}\right|
\end{aligned}
$$

і початковими маркуваннями: $m\left(P_{01}\right)=1, m\left(P_{02}\right)=0, \ldots, m\left(P_{0 l}\right)=0, m\left(P_{1 i}\right)=1$, де $1 \leq i \leq k$, $m\left(P_{j}^{\prime}\right)=n_{j}+i m_{j}$, де $1 \leq j \leq l, m\left(P_{2 j}\right)=0$, де $1 \leq j \leq l$.

Застосування моделі 'S розглянуто на прикладі 2.

Приклад 2. На рис. 5 наведено модель переставлення групи вагонів 3 приймально-відправної (П-В) колії на сортувально-відправну (С-В) колію. Позиції ' $P_{11}$, ' $P_{12} i{ }^{\prime} P_{13}$ моделюють приймальновідправні колії вантажних поїздів, а позиції $P_{2 j}$, де $1 \leq j \leq 4$, моделюють сортувально-відправні колії. На приймально-відправних коліях 1, 2 і 3 відповідно знаходяться 36 вагонів, 24 вагони і 21 вагон. Іншими словами, $m\left({ }^{\prime} P_{11}\right)=36, \quad m\left({ }^{\prime} P_{12}\right)=24 \quad$ i $m\left({ }^{\prime} P_{13}\right)=21$. Ознаки переставлення груп вагонів 3 приймально-відправних колій на сортувальновідправні задаються відповідно маркованнями $m\left(P_{01}\right)=1, \quad m\left(P_{02}\right)=0, \quad m\left(P_{03}\right)=0$, $m\left(P_{04}\right)=0$. Післяумовні комплексні позиції задаються так: $m\left(P_{1}^{\prime}\right)=13+i 21, m\left(P_{2}^{\prime}\right)=11+i 19$, $m\left(P_{3}^{\prime}\right)=12+i 14, \quad m\left(P_{4}^{\prime}\right)=11+i 17 . \quad$ На сортувально-відправних коліях 1, 2, 3 і 4 відповідно підготовлені 24 вагони, 33 вагони, 21 вагон і 16 вагонів. Іншими словами, $m\left(P_{21}\right)=24, m\left(P_{22}\right)=33$, $m\left(P_{23}\right)=21$ і $m\left(P_{24}\right)=16$. Переставлення груп вагонів 3 приймально-відправних колій на сортувальновідправні відповідно задаються тривалостями $f\left(P_{01}\right)=0, \quad f\left(P_{02}\right)=1, \quad f\left(P_{03}\right)=1 \quad$ i $f\left(P_{04}\right)=1$. Загалом переходи $T_{i} \in T$ імітують переходи $t_{1 i}$, де $1 \leq i \leq 3, t_{j}$, де $1 \leq j \leq 4, \mathrm{i} t_{2 \mathrm{j}}$, де $1 \leq j \leq 4$. 


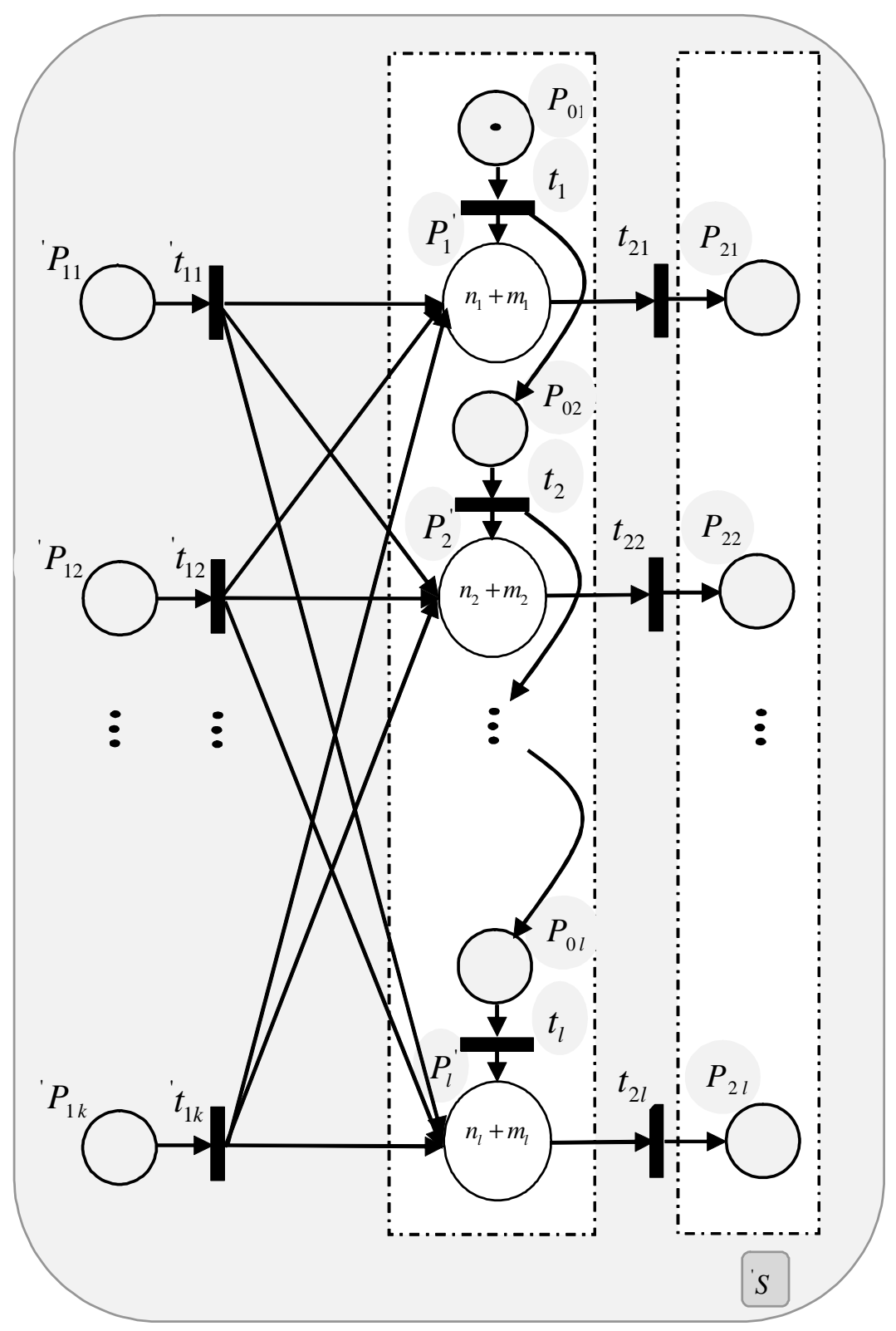

Рис. 4. Модель на базі підмережі ' $S_{\mathrm{Pr}}$

Динаміку технологічних процесів роботи моделі $S$ продемонстровано в табл. 2. 


\begin{tabular}{|c|c|c|c|c|c|c|c|c|c|c|c|c|c|}
\hline \multirow{18}{*}{ 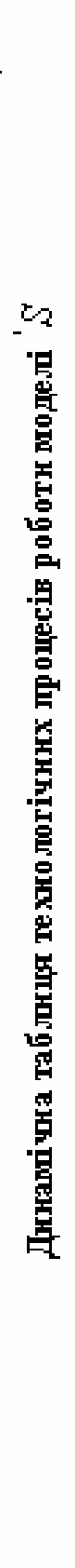 } & $\mathrm{D}_{-1}^{\mathrm{H}}$ & $\Xi$ & 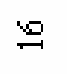 & 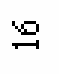 & $\Xi$ & $\Xi$ & $\Xi$ & $\Xi$ & $\Xi$ & $\Xi$ & $\Xi$ & 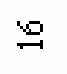 & $m$ \\
\hline & $\mathrm{D}_{-1}^{\mathrm{Q}}$ & $\theta$ & $\nabla$ & $\theta$ & $\nabla$ & $\vec{\theta}$ & $\nabla$ & $\nabla$ & $\theta$ & 可 & 哲 & 可 & y \\
\hline & $\mathrm{D}_{-1}^{\mathrm{a}}$ & 9 & 9 & $m$ & 9 & $\infty$ & 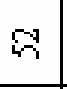 & 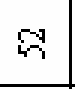 & $\mathrm{N}$ & 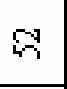 & $\mathrm{N}$ & 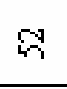 & $\mathrm{s}$ \\
\hline & $0_{-1}$ & 思 & $\nabla$ & 5 & 9 & 9 & 9 & 9 & 9 & 5 & 于 & 9 & 5 \\
\hline & $\mathrm{O}_{-1}^{+}$ & 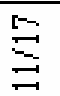 & 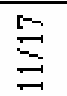 & 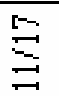 & $\stackrel{5}{\Xi}$ & $\begin{array}{l}\mathrm{O} \\
\vdots \\
\Xi\end{array}$ & $\stackrel{5}{=}$ & $\stackrel{10}{=}$ & $\begin{array}{ll}\mathrm{r} \\
= \\
=\end{array}$ & $\stackrel{\mathrm{I}}{\Xi}$ & 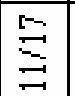 & 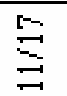 & 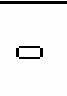 \\
\hline & $\mathrm{D}_{-1}^{m}$ & $\mathrm{~d}$ & 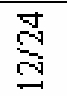 & 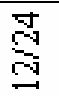 & 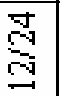 & $\mathrm{N}$ & 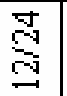 & 9 & $\mathrm{~d}$ & $=$ & $=$ & $\square$ & $=$ \\
\hline & $D_{-1}^{\infty}$ & $\stackrel{2}{9}$ & 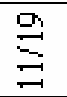 & 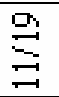 & $\begin{array}{l}9 \\
\Xi \\
\Xi\end{array}$ & \begin{tabular}{l}
9 \\
$\vdots$ \\
\hdashline
\end{tabular} & $\square$ & $\square$ & $\square$ & $\square$ & $\square$ & $\square$ & $\square$ \\
\hline & $\mathrm{O}_{-1}^{-1}$ & 8 & $\overrightarrow{9}$ & $=$ & $=$ & 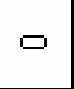 & $=$ & $=$ & $=$ & $\square$ & $=$ & $\square$ & $=$ \\
\hline & $\sigma_{1}$ & $\nabla$ & $=$ & $\square$ & $=$ & $\square$ & $=1$ & $\square$ & $\square$ & $=$ & $\square$ & $=$ & $\square$ \\
\hline & $0^{9}$ & $\mathbb{N}$ & $\underset{\nabla}{ }$ & 寸 & $\mathbb{v}$ & $\mathbb{v}$ & 団 & $\mathbb{N}$ & $=$ & $=$ & $=$ & $=$ & $\square$ \\
\hline & $a_{-1}^{-}$ & 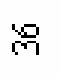 & 9 & 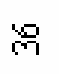 & 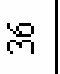 & $\stackrel{\mathrm{r}}{-}$ & $\stackrel{-}{a}$ & $\mathrm{~m}$ & $\stackrel{\mathrm{r}}{=}$ & $\stackrel{-}{a}$ & $\mathrm{r}$ & $=$ & $\square$ \\
\hline & \pm & $\square$ & $=$ & $\square$ & $=$ & $=$ & $=$ & $\rightarrow$ & $\rightarrow$ & - & $=$ & $\square$ & $=$ \\
\hline & $\sigma_{1}$ & 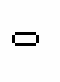 & $\square$ & $\sigma$ & -1 & - & -1 & $=$ & $=$ & $=$ & $\theta$ & $=$ & $=$ \\
\hline & ${ }_{0}^{9}$ & - & - & - & $\square$ & $\square$ & $\square$ & $\square$ & $\square$ & $\square$ & $\square$ & $\square$ & $\square$ \\
\hline & 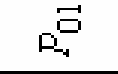 & $\square$ & $\square$ & $\square$ & $=$ & $\square$ & $\square$ & $\square$ & $\square$ & $\square$ & $\square$ & $\square$ & $\square$ \\
\hline & $E-1$ & $\rightarrow$ & $-\infty$ & $\overrightarrow{3}$ & 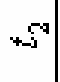 & $-\overrightarrow{-1}$ & 9 & 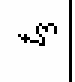 & -9 & +9 & $--^{+}$ & $-\overrightarrow{+1}$ & $+\vec{H}$ \\
\hline & $\mathrm{H} \cdot \mathrm{O}$ & $=$ & $=$ & 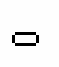 & -1 & -1 & - & $\infty$ & $\leftrightarrow$ & 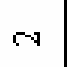 & $m$ & $m$ & $m$ \\
\hline & 要思 & $\rightarrow$ & 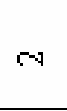 & $m$ & 寸 & $m$ & 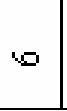 & $\cdots$ & $\infty$ & $a$ & $\Xi$ & $\Rightarrow$ & 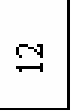 \\
\hline
\end{tabular}




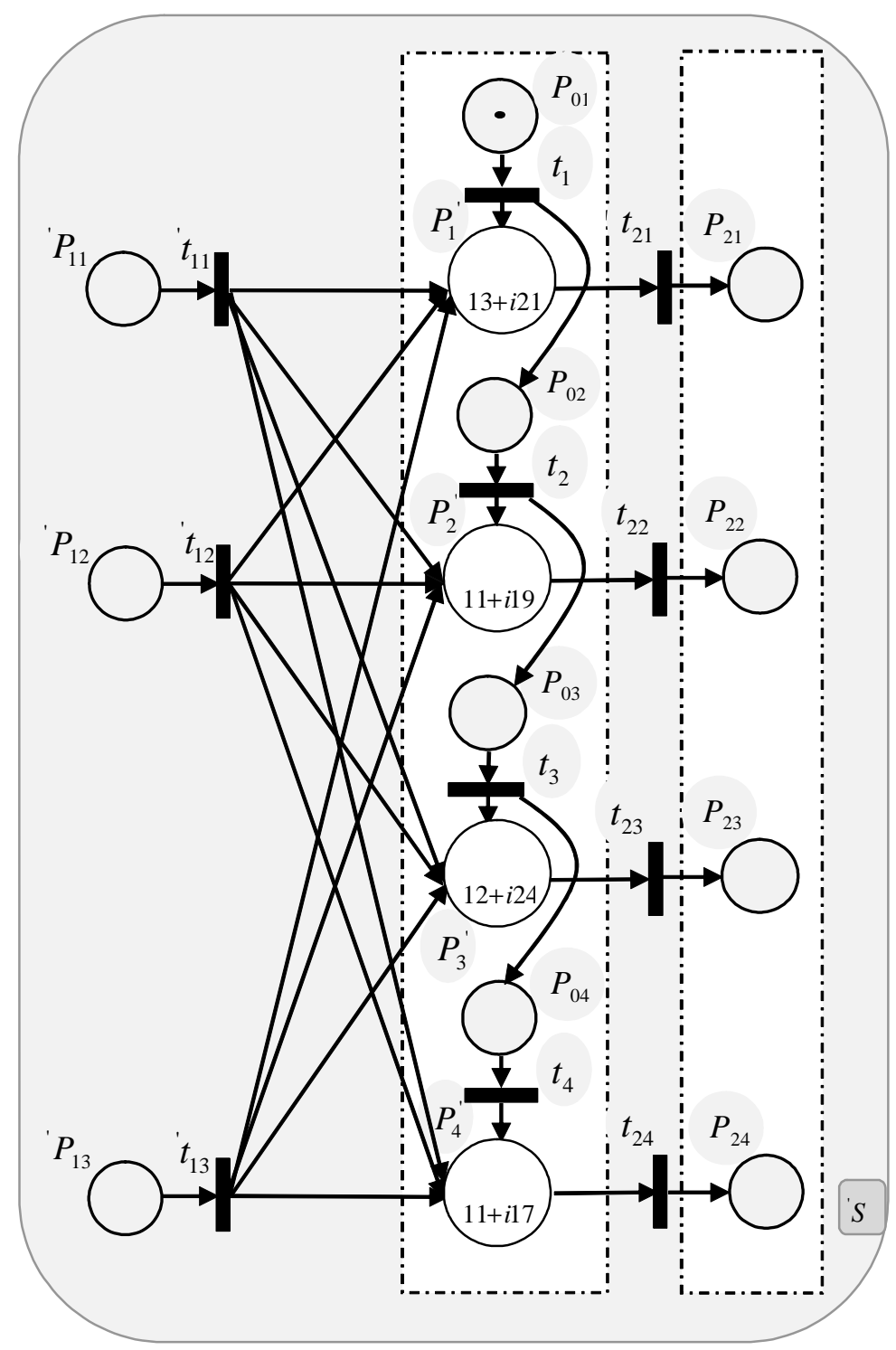

Рис. 5. Модель переставлення групи вагонів з П-В колії на С-В колію

\section{Висновки}

1. Розширено можливості комплексної позиції виду $n-i m$ (вихідна предикатна позиція).

2. Розроблено комплексну позицію виду $n+i m$ (вхідна предикатна позиція).

3. Реалізовано механізм роботи комплексних позицій видів $n-i m$ і $n+i m$.

4. Описано динаміку функціонування комплексних позицій $n-i m$ і $n+i m$.

5. На прикладах обгрунтовано мету застосування введених комплексних позицій виду $n-i m$ і $n+i m$.

\section{Список використаних джерел}

1. Селецький В. С., Федак Я.А. Про пристрої обслуговування заявок. Іформачійно-керуючі системи на залізничному транспорті. 2001. № 5. C. $31-34$.

2. Селецький В. С. Застосування математичного апарату мереж Петрі на залізничному транспорті. Залізничний транспорт Украӥни. 2009. № 2. C. $3-6$.

3. Селецький В. С. Розширення мереж Петрі. Частина I. Означення, моделі та їх математичний опис. Іформаційно-керуючі системи на залізничному транспорті. 2011. № 5. С. 77 - 80 .

4. Селецький В. С. Розширення мереж Петрі. Частина II. Обгрунтування, властивості і аналіз. 
Іформаційно-керуючі системи на залізничному mpaнcnopmi. 2011. № 6. С. 31 - 36 .

5. Селецький В. С. Розширення мереж Петрі. Частина V. Можливості позицій мереж Петрі. Іформаційно-керуючі системи на залізничному транспорті. 2014. № 5 . С. 75 - 80 .

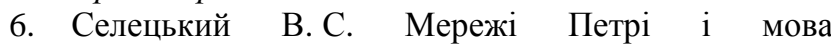
програмування Delphi. Iформачійно-керуючі системи на залізничному транспорті. 2014. № 2. C. $15-20$.

7. Reisig, W. Petri nets - an introduction : EATCS Monographs on Theoretical Computer Science 4. Springer Verlang, 1985.

8. Corsi F. and Castagnolo B. Probablistie delay evaluation in combinational digital circuits by Petri nets. Microelectronics and Reliab. 1983. Vol. 23, No. 3. P. 541-553.

9. Florin G., Franze C. and Natkin S.. Stochastic Petri nets: properties, aplications and tools. Microelectronics and Reliab. 1991. Vol. 31, No. 4. P. 669-697.

10. Po-Zung Chen, Steven C. Bruell and Giarfranco Balbo. Formulating and solving optimization problems using stochastic timed Petri nets. Microelectronics and Reliab. 1991. Vol. 31, No. 4. P. 769-792.

11. Zuberek W. M. M-timed Petri nets, premptions, and performance evaluation of systems. Advances in Petri Nets 1985 :Lecture Notes in Computer Science 222, G. Rosenberg(ed.). Springer Verlag, 1986. P. 478-498.

12. Zuberek W. M. Timed Petri nets definitions, properties, and applications. Microelectronics and Reliab. 1991. Vol. 31, No. 4. P. 627-642.

Селецкий В. С. Сети Петри и комплексные числа. Аннотация. В статье проведено расширение возможностей комплексной позиции вида $n-i m$ (выходная предикатная позиция), разработана комплексная позиция вида $n+i m$ (входная предикатная позиция) и реализован механизм работы комплексных позиций видов $n-i m$ и $n+i m$.

Проведенные расширения сетей Петри на основании построенных подсетей с предусловной комплексной позицией вида $n$-im и постусловной комплексной позицией вида $n+i m$ описано с помощью математической терминологии, отображено c помощью графических интерпретаций и проиллюстрировано их применение на примерах.

Ключевые слова: модель, расширенная сеть Петри, выходная предикатная позиция, входная предикатная позиция, комплексная позиция вида $n-i m$, комплексная позиция вида $n+i m$.
Seletsky V.S. Petri nets and complex numbers.

Abstract. In this article, the original predicate position (use of complex species positions $n$-im) has been improved by the goal. A prerequisite subnet was constructed based on the initial complex position of the species $n-i m$. The prerequisite subnet is described in mathematical language and is represented by graphical interpretation.

The dynamics reproduces the technological processes of the model, which was developed on the basis of a prerequisite subnet (using complex views of the species $n-i m)$. The above model, which uses a prerequisite subnet, is illustrated and analyzed with an example with specific data.

The need to develop a new population of the position type - the input predicate position - was realized. On the basis of the input complex position of the species $n+i m$, a post-conditional subnet is developed. The newly introduced post-conditional subnet is described in mathematical terminology and is represented by a graphical interpretation.

The work of the model, which is developed on the basis of a sub-conditional subnet (using complex views of the species $n+i m$ ) is described by means of a dynamic table of technological processes of the model. The model is illustrated and analyzed using a specific data example.

Introduced models that use a prerequisite subnet (built on the basis of the original complex view of the species $n-i m$ ) and a post-conditional subnet (built on the basis of the original complex position of the species $n+i m$ ) allow to build models from complex objects.

Key words: model, extended Petri net, output predicate position, input predicate position, complex view position, complex view position.

Надійшла 02.06.2020 p.

Селецький Василь Стасьович, кандидат технічних наук, провідний інженер виробничого підрозділу «Львівське відділення» філії «Головного інформачійно обчислювального иентру» акціонерного товариства «Укрзалізниця». E-mail: Selezkyj@ukr.net ORCID ID: https://orcid.org/0000-0001-6981-9450

Selezkyj Vasyl Stasovich, Candidate of Technical Sciences, Provincial Engineer of the Virobnichnoe pidrozdilu "Lvivske viddilennya" filis of the "Head Information and Obligatory Center" of the Ukrzaliznitsa Joint-Stock Partnership.E-mail: Selezkyj@ukr.net ORCID ID: https://orcid.org/0000-0001-6981-9450 